\title{
A 30-year retrospective: National Organization for Rare Disorders, the Orphan Drug Act, and the role of rare disease patient advocacy groups
}

This article was published in the following Dove Press journal:

Orphan Drugs: Research and Reviews

17 February 2014

Number of times this article has been viewed

\section{Mary Dunkle}

National Organization for Rare Disorders, Danbury, CT, USA

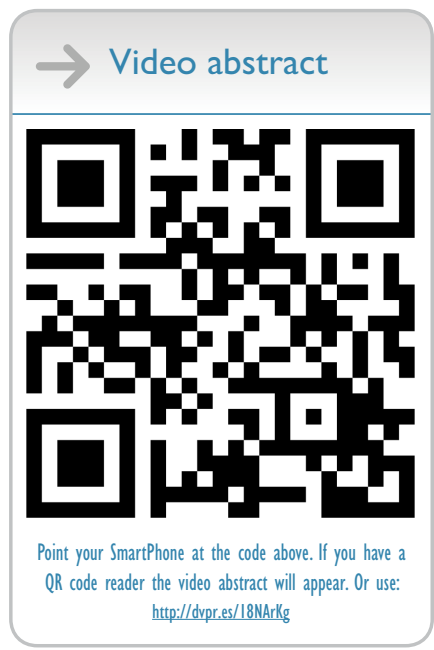

Correspondence: Mary Dunkle

National Organization for Rare Disorders, 55 Kenosie Ave, Danbury, CT 068 I0, USA Email mdunkle@rarediseases.org

\begin{abstract}
This 30-year retrospective looks at the history of the US Orphan Drug Act and how it originally came to be enacted, with particular emphasis on the role of patient advocacy organizations. The article explores how rare-disease patient advocacy groups learned to work with government partners in the National Institutes of Health and US Food and Drug Administration, members of Congress, and the media to promote their cause. It also discusses their awakening to the value of collaboration, which led to the formation of an umbrella organization to represent their shared interests. Milestones over the years are briefly discussed, and current areas of focus for rare disease patient organizations - most notably, globalization - are also examined.

Keywords: rare diseases, orphan products, NORD, Rare Disease Day, global patient communities, EURORDIS, NZORD, TFORD, CORD, rare disease research
\end{abstract}

\section{Introduction}

The year 2013 marked the 30th anniversary of two significant events related to rare diseases and orphan products, ie, the enactment of the US Orphan Drug Act and the establishment of the National Organization for Rare Disorders (NORD). At an anniversary event hosted by NORD in May 2013, Congressman Henry Waxman of California, the primary author of the Orphan Drug Act, remarked that the law had been more successful than even he imagined at the time it was written.

While there are many factors contributing to the impact the Orphan Drug Act has had upon the development of therapies for people with rare diseases, the emergence of patient advocacy groups certainly is one of them. These organizations, which in many cases are "kitchen-table" groups formed by parents of patients or even patients themselves, have played, and continue to play, a very important role in the history of orphan product development in the US and around the world.

The history of patient advocacy groups in the US is also very closely entwined with the history of the Orphan Drug Act. To review how it all began, it is important to note that, during the 1970s, there were several individuals and organizations beginning to be aware of the need for an organized effort to encourage the development of treatments for people with rare diseases.

This included the US National Institutes of Health (NIH) and Food and Drug Administration (FDA), as well as a small number of disease-specific patient advocacy groups, most notably one representing patients with Huntington's disease that was established by Marjorie Guthrie, the widow of folksinger Woody Guthrie, who had died of the disease.

However, progress was limited until these individual entities found each other and began to recognize the value of collaboration in achieving their political goals. 
Understanding that awakening to the value of collaboration, and the resulting series of events, is essential to understanding today's global rare disease community and the role of patient organizations in orphan product development.

\section{How it began}

On June 29, 1979, a task force chaired by Marion Finkel of the US FDA, which is the agency of the US government that holds regulatory authority over pharmaceuticals, published a report ${ }^{1}$ calling for measures to address what it perceived as a significant public health issue. The issue was that drugs for small patient populations, termed drugs "of limited commercial value" in the report, were not being developed.

The members of the task force, all of whom served as volunteers, came mostly from the US FDA and NIH. They produced a report calling for direction of more resources toward the research, development, and distribution of drugs for people with rare diseases. This report helped set the stage for events that ultimately resulted in the Orphan Drug Act.

At about the same time, certain members of the US Congress were becoming aware of this problem as a result of receiving requests for help from their constituents. Two members of Congress who became concerned about the problem were Representative Henry Waxman and Senator Nancy Kassebaum of Kansas.

Representative Waxman was contacted by the mother of a young man who had Tourette syndrome and had been helped by an investigational drug that the company had decided to abandon because it was not proving effective against the more common disease for which it was being developed. Senator Kassebaum was contacted by a constituent affected by Huntington's disease. In both cases, the constituents had been encouraged to contact their members of Congress by patient advocacy organizations.

Abbey Meyers, who later played a key role in the establishment of NORD and served as the organization's president for its first 25 years, was affiliated with the Tourette Syndrome Foundation in the late 1970s and early 1980s because she had children with the syndrome. Meyers encouraged the family of Adam Seligman, the patient from Representative Waxman's district, to contact their Congressman. ${ }^{2}$

Similarly, Marjorie Guthrie was conducting outreach to Congress on behalf of the Huntington's disease patient community, and she encouraged patients and families to do the same, which resulted in the outreach to Senator Kassebaum.

Representative Waxman was chairing the Subcommittee on Health and the Environment of the House Energy and Commerce Committee at the time. He was so moved by the situation described by his constituent that he ultimately decided to hold hearings to gather information on "the orphan drug problem".

On March 8, 1982, the opening day of the hearings, Representative Waxman made the following public statement: "For those with rare diseases, this is a tragic, and sometimes hopeless, situation. For the rest of us who believe that people with rare diseases suffer no less and are no less deserving because they are so few, this situation is intolerable. It must be changed."

\section{Patients learned to be advocates}

Abbey Meyers and others representing the patient community spoke at the hearings. The patient representatives included some physicians, notably Jess Thoene of the University of Michigan and Melvin Van Woert of Mount Sinai Hospital in New York, who were treating patients with rare diseases and were supportive of the fledgling patient advocacy movement. Both Drs Thoene and Van Woert later served as medical advisers to NORD after it was formally established.

Most of the patient representatives were new to the world of politics and did not know how to advocate effectively. This includes Meyers, who later told her colleagues at NORD that Marjorie Guthrie, who had come onto the scene a few years earlier advocating specifically for people with Huntington's disease as a result of her family's experience with the disease, was generous in sharing what she had learned about how to interact with members of Congress and how to provide information that would be helpful to them.

The patient advocates also learned another important lesson during this period, ie, how to interact with the media and work with them to engage the public in a cause. After Meyers testified before Representative Waxman's subcommittee, she received a call from a television writer/producer, Maurice Klugman, who was the brother of Jack Klugman, an actor then starring in a popular television show about a medical examiner known as “Quincy ME”.

Maurice Klugman had a rare disease and both he and Jack Klugman felt that it was important for the Quincy ME television show to address substantive issues rather than just provide entertainment. Writers for the show, and eventually Jack Klugman himself, carried on extensive correspondence with Meyers to learn about the issue and incorporate the patient perspective into a script for an episode of the show. When the episode aired, it sparked a firestorm of interest, particularly from individuals and families affected by rare diseases. Jack Klugman received hundreds of letters, which he forwarded to Meyers. Those letters led to a mailing list for the ad hoc coalition that ultimately became NORD. 
Klugman was also invited by Representative Waxman to testify before the subcommittee. While it is not unknown today for Hollywood celebrities to appear on Capitol Hill, it was highly unusual at that time, and Klugman's appearance was widely reported in newspapers, including The New York Times. $^{3}$

On the evening before his testimony, Meyers and Dr Van Woert called Klugman at his hotel "because we knew that he was uncertain about his speech and needed advice", Meyers later wrote in a report to the Tourette Syndrome Foundation Board.

"Jack expressed a deep feeling that he was just an actor and he couldn't understand why he would have an impact on Congress. He said he had read our speeches from last year's testimony and had cried. He wondered if anything he could say to Congress could be more meaningful than what we had already said."

"Dr Van Woert and I explained that our speeches were given to a half-empty hearing room," Meyers wrote, adding that she and Dr Van Woert had told Klugman that the great difference between his testimony and theirs would be that his would gain far greater attention and that the press would report it. ${ }^{4}$

Based on the hearings and research by his staff, Waxman eventually wrote a bill that became the Orphan Drug Act. William Corr, who was a member of his staff at that time and significantly involved in this process, today is the Deputy Director of Health and Human Services, the agency within the US government with ultimate responsibility for all health-related matters.

Waxman was the primary sponsor of the bill in the House of Representatives. Senator Kassebaum became the primary sponsor in the Senate, with support from Senator Orrin Hatch and others.

At one point, when the bill appeared to be stalled in Congress, Klugman devoted a second episode of Quincy ME to the topic. This time, Meyers and others in the ad hoc patient coalition helped arrange for many real-life rare disease patients to serve as extras in the show, marching with signs and arms linked with Klugman in a simulated march on Washington.

Ultimately, through these collaborative efforts, the Orphan Drug Act was approved by the House of Representatives on December 14, 1982, and three days later, by the Senate. President Ronald Reagan signed the bill on January 4, 1983. At one point over the December holidays, when it appeared that the President might not sign the bill, the patient advocates placed a full-page advertisement in the Los Angeles Times (because the President was at his home in California at the time) urging him to sign the bill.

\section{Patients decided to formalize their ad hoc coalition}

Just before the Orphan Drug Act was enacted, the members of the patient coalition, all of whom represented disease-specific patient communities at that time, recognized that the Orphan Drug Act might never have become reality if they had not focused on their common ground and worked together to provide advocacy for it. They realized, as NORD's slogan states today: "Alone we are rare. Together we are strong." "тм

As a result, the ad hoc patient coalition decided to formalize as an umbrella organization representing all people with rare diseases. That organization was to be called NORD. Meyers was asked to serve as its president. The incorporation of NORD became official on May 4, 1983. Jack Klugman served as NORD's honorary chairman for the first few years. Rare disease medical experts who had supported the patient advocates during the Congressional hearings, including Drs Thoene and Van Woert, provided key leadership during the formation of NORD and continued as medical advisers for many years.

While there were relatively few disease-specific patient organizations in existence at the time of the founding of NORD, there are many today. NORD represents more than 200 disease-specific member organizations and partners with many other stakeholders in the rare disease community. The original member organizations included groups representing, among others, the Marfan syndrome, cystinosis, and epidermolysis bullosa patient communities.

Since 1983, the Orphan Drug Act has been amended on three occasions, in 1984, 1985, and $1988 .^{5}$ There has been discussion of amending it a few other times, but NORD has opposed such efforts out of concern that reopening the law might result in changes that would weaken it. Specific provisions of the Orphan Drug Act include:

- Seven years of marketing exclusivity for drugs and biologics that are being developed to treat people with rare diseases ("rare" being defined in the US as affecting fewer than 200,000 Americans)

- A $50 \%$ tax credit on the costs of developing products designated as orphans

- Federal grants for the development of orphan products through the US FDA Orphan Products Development grants program and additional guidance from the US FDA during the drug development process. 
The Orphan Drug Act is widely considered to have been successful, and both Waxman and Kassebaum issued statements at the May 2013 anniversary celebrations indicating that the law had exceeded even their expectations. While only ten drugs for rare diseases were developed solely by industry during the decade before 1983, more than 2,000 have been designated orphans since then and approximately 450 have been approved. ${ }^{6}$

\section{Milestones since I 983}

In the late 1980s, the US Congress established a National Commission on Orphan Diseases. The Commission's report issued in 1989 has become a classic document in the history of rare diseases and orphan products. In the prologue, Dr Thoene, who chaired the commission, wrote:

"Hidden among the many strident voices clamoring to be heard

by Congress and to receive a share of our national resources is the persistent murmur of those left outside the current health care system. Lacking adequate health insurance, a correct diagnosis, and any rare hope of effective therapy, persons with rare diseases are truly medically disenfranchised."

The report documented a continuing need for a national effort to address issues such as delay in obtaining an accurate diagnosis, the financial impact of having a rare disease on patients and their families, and lack of access to therapies. ${ }^{7}$ Stephen C Groft served as executive director for the commission and subsequently was named director of the NIH Office of Rare Diseases Research, where he has served for many years as the $\mathrm{NIH}$ liaison with rare disease patient advocacy organizations.

The NIH Office of Rare Diseases Research has played a pivotal role in connecting patient advocacy organizations with the NIH, which is the primary government funder of medical research in the US. Dr Groft and his staff have provided a channel through which patient advocates could articulate their needs and concerns to senior government officials. The NIH Office of Rare Diseases Research has also provided funding for numerous disease-specific conferences, in partnership with patient advocacy organizations, and played a key role in assuring that patient advocacy groups would be included as partners with researchers in the NIH Rare Diseases Clinical Research Network (see below).

In addition to the establishment of the NIH Office of Rare Diseases Research, other milestones over the years have included:

- Establishment of the ClinicalTrials.gov website, where all studies receiving funding from the US government must be listed; NORD and other patient advocacy groups voiced a need for a central location where patients could learn about clinical trials for rare diseases

- The Rare Diseases Act of 2002, which led to establishment of the NIH Rare Diseases Clinical Research Network, through which grant recipients are required to include patient advocacy groups in the planning and implementation of their research

- Publication by patient advocacy groups of numerous resources to increase awareness among physicians and other medical professionals of rare diseases; this includes publication by NORD of two editions of The Physician's Guide to Rare Diseases (Dowden Publishing) and a 2003 edition of The NORD Guide to Rare Disorders (Lippincott, Williams and Wilcott) as textbooks for physicians

- Establishment of an associate director for rare diseases position in the US FDA's Center for Drug Evaluation and Research, for which NORD and its member organizations provided advocacy

- Establishment and later expansion of a "COMPASSIONATE ALLOWANCES PROGRAM" within the US Social Security Administration to provide expedited review of applications for disability assistance from individuals with certain severely disabling conditions; NORD and its member organizations were honored by the Social Security Commissioner for helping make this program possible

- Inclusion in the US Affordable Care Act of provisions eliminating annual and lifetime insurance caps, discrimination based upon pre-existing medical conditions, and the ability of insurers to discontinue coverage for individuals with dire diagnoses; rare disease patient organizations provided strong advocacy to assure that these provisions would be included in the bill that ultimately became the Affordable Care Act.

A major milestone in 2012 was the approval by the US Congress and subsequent signing by President Obama of the US FDA Safety and Innovation Act. This law was the culmination of the reauthorization of the Prescription Drug User Fee Authorization. The law and the process leading up to it expanded the US FDA's Rare Disease Program and provided other key provisions related to accelerating orphan product development.

\section{Globalization of patient advocacy}

After the Orphan Drug Act was enacted in the US, similar legislation was enacted in some other countries. Over the years, the patient advocates who founded NORD in the US have shared their experiences with patient advocates in 
other parts of the world related to orphan drug legislation and founding an umbrella organization to represent patients. NORD's president also provided advice to contacts in Europe during the establishment of the European Organisation for Rare Diseases (EURORDIS). In turn, the chief executive officer of EURORDIS, Yann Le Cam, has emphasized the importance of globalization through his leadership in initiatives such as establishing a global Rare Disease Day, which is now observed in more than 60 countries.

In recent years, the importance of global connection among rare disease patient advocacy organizations has become increasingly clear. Many disease-specific organizations today have an international component and seek ways to overcome language and geographical challenges to work together on behalf of patients. Organizations such as the Prader-Willi Syndrome Association in the US work closely with their counterparts in other countries through international alliances.

National federations of patient advocacy organizations are also seeking ways to work together to promote their shared goals and mission. As an example, NORD and EURORDIS signed a memorandum of understanding in 2009 to work together on several initiatives, including RareConnect ${ }^{\mathrm{TM}}$, a platform cohosted by NORD and EURORDIS with their disease-specific member organizations, for global online communities for patients and families.

To date, there are 45 disease-specific communities on this platform at http://www.RareConnect.org. Information may be translated into any of five languages (English, French, German, Italian, and Spanish). Patients and caregivers may use the site to share information and encouragement. Patient organizations may post their disease-specific information.

The intention of RareConnect is to provide a safe online location, hosted by trusted patient advocates, for diseasespecific global connection of patients and caregivers. Other national alliances, such as the Canadian Organization for Rare Disorders (www.rarediseases.ca), Taiwan Foundation for Rare Disorders (http://www.tfrd.org.tw/tfrd/), and New Zealand Organisation for Rare Diseases (http://www.nzord. org.nz/), frequently interact with EURORDIS and NORD. Also, while most NORD members are based in the US, a few, such as Parent-to-Parent New Zealand (http://www.parent2parent.org.nz/), are based outside the US and are active in both their national alliances and in NORD.

Rare Disease Day, established in Europe by EURORDIS in 2008, is one of the most successful initiatives to promote global collaboration among rare disease patient advocacy organizations. It is observed on the last day of February each year (February 29 in leap years; February 28 in other years).
Each participating country has a national sponsor, and a global planning team organized by EURORDIS selects a theme and activities each year so that patient advocates around the world are articulating the same messages and highlighting the same activities. For 2014, the focus will be on caregiving. A video is being created to be used by all participating global organizations. NORD has been asked to develop a message each national sponsor can post just after midnight in local time to announce Rare Disease Day.

While much of the global activity by rare disease patient advocacy organizations focuses on awareness and public policy, this connection is also potentially very important for research and, specifically, for clinical trial recruitment and participation.

Recognizing that timely diagnosis remains a serious problem in the rare disease community, the patient advocacy organizations increasingly are also combining their efforts in the area of physician education. Many disease-specific patient organizations work with their medical advisers to develop awareness/educational materials specifically for physicians and other medical professionals. Working with disease-specific organizations, NORD launched a website for this purpose in 2012 at http://www.NORDphysicianguides. org. Information posted here is written by rare disease medical experts for physicians. NORD and its patient advocacy partners promote awareness of the site. Between March 2012 and August 2013, the website received visits from physicians in 133 countries.

\section{Advocates encourage establishment of national federations}

Based on their own experiences, the leaders of NORD, EURORDIS, and other national federations encourage disease-specific patient advocacy organizations in other countries to establish a national umbrella organization to unite rare disease patient advocates. In 2012, representatives of NORD and the Genetic Alliance, a US organization representing advocacy groups for those with genetic diseases, participated in a conference in Freemantle, Australia, organized by the public health service of Western Australia at which a national strategy for rare diseases and orphan products for Australia was discussed. A representative of EURORDIS participated by video conference. ${ }^{8}$ A representative of EURORDIS also participated by video conference in the first-ever community-wide rare disease and orphan product conference to be organized in Brazil by a patient organization known as AMALVI, with partners in the public health sector and at South American universities. 
In addition, established patient advocacy groups have been informally advising an organization being developed to promote awareness of rare diseases and the needs of patients in India. Called the Indian Organization for Rare Disorders, this organization is being established by a University of Minnesota faculty member, working with his contacts among academics and patients in India.

Global collaboration is also taking place among other stakeholder groups not specifically limited to patient organizations. The International Conference on Rare Diseases and Orphan Products was established in 2005 to host global conferences drawing together government research institutes, academic partners, and patient organizations.

In recent years, the US FDA and NIH in the US, and their counterparts in other countries and particularly in the European Union, have made an effort to work together more closely to promote a more seamless research and regulatory environment related to rare diseases. Specific achievements include the adoption in the US and European Union of a joint orphan designation application and planned cohosting of orphan designation workshops.

In January 2013, NORD and the Japan Patients Association signed a memorandum of understanding to work together to promote connection among rare disease patients and patient advocacy organizations in the US and Japan. For the signing ceremony, the Japan Patients Association president, Tateo Itoh, traveled to the US and met with NORD president and chief executive officer, Peter L Saltonstall, in Washington DC.

Among the first projects to be adopted by NORD and the Japan Patients Association is an initiative to cross-reference disease-specific organizations that are members of the two federations and introduce them to each other if they are not already working together. The Japan Patients Association also has a memorandum of understanding with EURORDIS, as does the Canadian Organization for Rare Disorders.

\section{Patient advocacy organizations and research}

One of the areas in which the role of patient advocacy organizations has increasingly come to be seen as of critical importance is research. For many years, patient advocacy groups have been a primary source of funding for research on extremely rare diseases. More recently, these groups are also recognized as playing an increasingly important role in the design and implementation of studies.
Examples of patient organizations that support research on rare diseases include the LAM Foundation, which in 2012 was cited as a model for the interaction between patient advocates and researchers in The New England Journal of Medicine. Founded by the parents of a young woman diagnosed with this progressive, often fatal lung disease, the foundation has raised more than US\$16 million for research, created a global registry, and supported a successful repurposing trial of the drug sirolimus. ${ }^{9}$

The National PKU Alliance, Batten's Disease Research Foundation, International WAGR Syndrome Association, and Erdheim-Chester Disease Global Alliance are other examples of patient advocacy organizations that have been very proactive about connecting with researchers and finding effective ways to support and promote their work. NORD established a research program in 1995 because many of its members had raised money for research but did not have the structure to be able to award and properly oversee grants. NORD is able to do so because its scientific and medical advisory committee (SMAC) is willing to oversee such a program. The members of NORD's SMAC, who all serve as volunteers, are rare disease medical experts in various settings, primarily universities and teaching hospitals, around the US.

At least once a year and sometimes more frequently, NORD advertises funding opportunities, based on donations made to disease-specific restricted research funds. The SMAC reviews letters of intent and abstracts, and selects applicants to be invited to submit full proposals. The SMAC later reviews proposals, selects those to fund, and then reviews the researcher's progress and final reports to assure a high quality of work.

In many cases, these grants represent the only funding available for particularly rare diseases. Fundraising for the grants is done by patient organizations or even individual patients and families. In several cases, individual families raise US $\$ 100,000$ or more to support research on specific rare diseases.

The NORD grants have resulted in numerous journal articles and at least one US FDA-approved product, ie, the titanium rib developed for children with any of several rare disorders resulting in thoracic insufficiency syndrome.

In addition to this critical financial support for research, patient advocacy organizations have increasingly come to be seen as playing a vital role in the establishment of patient registries, natural histories, and other resources necessary to support and encourage research. Recent examples of patient organizations with roles in research that helped bring new orphan therapies to market include the following: 
In January 2012, the US FDA approved Kalydeco ${ }^{\mathrm{TM}}$ (Vertex Pharmaceuticals Inc, Cambridge, MA, USA) for the treatment of cystic fibrosis patients with a specific genetic mutation. This was considered a breakthrough therapy for several reasons, including:

- for the $4 \%$ of patients with the specific mutation indicated, the drug treats the underlying disease and not just the symptoms

- Kalydeco ${ }^{\mathrm{TM}}$ is considered a model of how properly designed clinical trials and an understanding by all involved of effective use of personalized medicine can result in a treatment that has significant impact for a specific patient audience; if the drug had been reviewed as a potential therapy for all cystic fibrosis patients, it would not have been approved

- development of this drug also represented a successful partnership between a patient advocacy organization, the Cystic Fibrosis Foundation, and a company, Vertex Pharmaceuticals Inc; the foundation recognized early on the importance of establishing a patient registry and promoting patient participation in the search for a treatment; the patient-industry partnership was so successful that even the US FDA mentioned it at the time the drug was approved, and Janet Woodcock, a senior US FDA official, wrote a blog on this topic at the time. ${ }^{10}$

Another recently approved product that represents a highly successful partnership, in this case a partnership involving more than one patient advocacy organization, NIH researchers, and a company, Sigma Tau Pharmaceuticals (Gaithersburg, MD, USA), is Cystaran ${ }^{\mathrm{TM}}$ eye drops, that were developed to prevent loss of vision or even total blindness among patients with cystinosis. There was already a US FDA-approved drug for cystinosis, but it cannot prevent the buildup of crystals in the patient's eyes. With support from the patient advocacy organizations for patients with cystinosis, a research team at NIH did the initial research to address this problem, and the company carried through to develop the orphan product, do the necessary testing to get it approved by the US FDA, and make it available to patients.

As the mother of a patient noted at the NORD anniversary celebration in May 2013, the company would not benefit financially from this product because of the small number of patients. However, even though the process of getting the product approved took many years, the patient organizations, NIH researchers, and company did not desert the effort or their collaboration because of the obvious benefit to patients. "My daughter is able to see today because of this sustained effort," the mother, MaryBeth Krummenacker, said at the NORD anniversary event.

\section{Patient advocates also play a growing role in access to treatments}

In addition to advocating for fair public policies and supporting research, both financially and in other ways, many patient advocacy organizations become involved in helping patients access treatments.

NORD established the first-ever patient assistance program specifically for medical treatments in 1987 at the request of a judge in a situation involving a drug shortage. Since then, NORD has administered hundreds of patient assistance programs providing millions of dollars of free drug, copay assistance, travel assistance to participate in clinical trials, and other types of assistance.

As of this writing, NORD is setting up a Patient Assistance Program (PAP) to pay for required basic rare disease testing for patients who qualify for the NIH Undiagnosed Diseases Program but do not have the resources to pay for the required pre-program testing.

As state and federal agencies struggle with tough economic times, patient advocacy organizations continue to remind state and federal officials who oversee programs related to patient access to medical care, such as state-administered Medicaid services for children and adults, of the seriousness of specific diseases and the need for patients to have access to therapies that may be life-saving in many cases.

For Rare Disease Day 2013, one of the primary initiatives in the US was "State House Events" through which patient organizations in each of several states collaborated to host events for their state legislators to educate them about the need for access to treatments since many important access decisions occur at the state level. Patients and parents of patients spoke at these events. Media coverage made the public aware of them. Such events were organized in Massachusetts, New Jersey, Connecticut, California, and Texas.

In the US, a tax reform proposal circulating in Congress during the summer of 2013 came to the attention of patient advocates because it would eliminate all tax credits, including the Orphan Drug Tax credit, which is a major provision of the Orphan Drug Act. While the proposal has not yet taken the shape (as of this writing) of legislation, the patient advocacy organizations proactively articulated their concern to Congress by signing a letter hand-delivered to key members of Congress by NORD. More than 70 advocacy organizations signed the letter, which included a quote from 
Marlene Haffner, the former director of the US FDA's Office of Orphan Product Development, attesting to the importance of the tax credit.

\section{Outlook for the future}

The role of patient advocacy organizations, which has grown significantly since the establishment of a formalized rare disease community in 1983, appears likely to continue to grow and become more diverse in the foreseeable future. With rare diseases, the opportunities for patients and patient organizations to drive palpable progress have been clearly demonstrated.

Social media provide important tools and resources for patients to connect, communicate, fundraise, and raise awareness. This has leveled the playing field so that even individuals with the rarest of medical conditions can find others in similar circumstances, connect with scientists interested in their diseases, and share their stories with individuals in industry or the investment community who may see opportunities that otherwise would not come to their notice.

As the US implements the Affordable Care Act and several other countries around the world develop national health care plans specifically related to rare diseases, patient advocacy groups by necessity will play a watchdog role to assure that the needs of their constituents are understood and properly addressed.

Accelerating the development of therapies through the use of alternative regulatory pathways and procedures remains a topic of discussion (sometimes heated) and will be an important part of the ongoing global conversation about how best to encourage the development of safe, effective treatments. In the US, the FDA, through its Office of Orphan Products Development and other entities within its Rare Disease Program, has increasingly sought input from patient organizations. Currently, this is most evident in activities related to the US FDA's patient-focused drug development initiative, which includes a series of public hearings.

Cost, too, is an increasingly important topic in this conversation. Patient advocates have focused primarily on promoting the development of treatments to date. However, calls for pricing to be set at a level that is sustainable are being heard from all sides. Absent from this conversation at the present time are any hard data comparing the lifetime cost of caring for patients who are not receiving effective treatment versus the cost of developing and providing the treatment. At this time, patient advocacy groups remain focused on the fact that there is no approved treatment for most of the 7,000 known rare diseases and that companies willing to take on the risk of developing orphan products must be compensated adequately or interest in orphan markets will wane.

For many years, rare disease patient advocates focused on stimulating the interest of academic researchers and pharmaceutical/biotechnology companies in learning about rare diseases and developing treatments for those affected. Patients and parents of patients affected by extremely rare diseases still live with the reality of few or no treatments and little or no research.

In today's global economy, questions related to allocation of resources have been added to this difficult situation. Increasingly, patient advocates representing those with extremely rare diseases are having to defend their advocacy to those who question whether it is ethical to devote limited resources to small patient populations when they might otherwise be applied to larger populations. An examination of this issue written by a member of NORD's SMAC, Doris Zallen, who is a bioethicist, is published on the NORD website. ${ }^{11}$

At the 2011 US Conference on Rare Diseases and Orphan Products, NIH Director Francis Collins noted that the science of rare diseases is advancing faster than at any other time during his career. With this explosion of scientific knowledge, combined with the high level of health care reform and public policy activity in progress around the world, the need for patient engagement and involvement has never been greater. Patient advocacy organizations provide a framework through which that engagement can be focused and formalized to serve as the greatest possible force for good in the lives of the millions of people around the world living with rare diseases.

\section{Disclosure}

The author reports no conflicts of interest in this work.

\section{References}

1. Finkel M. Significant drugs of limited commercial value. Report of Interagency Task Force to the Secretary of Health, Education and Welfare. 1979. Available from: http://rarediseases.info.nih.gov/files/1979_Interagency_Task_Force_Report_on_Significant_Drugs_of_Limited_Clinical_Value.pdf. Accessed October 31, 2013.

2. Rao G. Video interview with Abbey Meyers for US Food and Drug Administration event marking the 30th anniversary of the Orphan Drug Act. 2013. Available from: http://www.youtube.com/ watch?v=QGGc5YpyiV4. Accessed December 4, 2013.

3. Waxman H. The Orphan Drug Act. In: The Waxman Report: How Congress Really Works. New York, NY: Grand Central Publishing; 2009.

4. Meyers A. Report to Tourette Syndrome Board of Directors. 1981.

5. Villarreal M. Orphan Drug Act: Background and proposed legislation in the 107th Congress. CSR Report for Congress. Code RS20971. Washington, DC, USA: Congressional Research Service, The Library of Congress; 2001. 
6. US Food and Drug Administration. Search Orphan Designations and Approvals. Available from: http://www.accessdata.fda.gov/scripts/ opdlisting/oopd/. Accessed October 31, 2013.

7. Thoene J, Crooks G. Report of the National Commission on Orphan Diseases. 1989. Available from: http://rarediseases.info.nih.gov/ files/Report_of_the_National_Commission_on_Orphan_Diseases_ February_1989.pdf. Accessed October 31, 2013.

8. Rosenbaum L. How much would you give to save a dying bird? Patient advocacy and research. N Engl J Med. 2012;367:1755-1759.
9. Dawkins HJ, Molster CM, Youngs LM, O’Leary PC. Awakening Australia to rare diseases. Orphanet J Rare Dis. 2011;6:57.

10. Woodcock J. How science and strategic collaboration led to a new "personalized" cystic fibrosis treatment for some patients. FDA Voice. January 31, 2012. Available from: http://blogs.fda.gov/fdavoice/index. php/author/fda_voice/page/7/. Accessed October 31, 2013.

11. Zallen D. Can our society afford to provide treatments for people with rare diseases? Available from: http:/www.rarediseases.org/news-events/ news/zallen-2012/. Accessed October 31, 2013.

\section{Publish your work in this journal}

Orphan Drugs: Research and Reviews is an international, peer-reviewed, open access journal publishing original research, reports, reviews and commentaries on all areas of the design and development of orphan drugs for the treatment of rare diseases through to clinical applications. Clinical outcomes, patient safety, and programs for the development and effective, safe, and sustained use of medicines will be a feature of the journal. The manuscript management system is completely online and includes a very quick and fair peer-review system, which is all easy to use. Visit http://www.dovepress.com/testimonials.php to read real quotes from published authors.

Submit your manuscript here: http://www.dovepress.com/orphan-drugs-research-and-reviews-journal 